\section{Ingram, J. Murphy}

Centre for Health Informatics and Multiprofessional Education (CHIME), University College London Medical School, London, United Kingdom

\title{
Education and Training
}

\section{Integrating Informatics into the Undergraduate Curriculum: A Report on a Pilot Project}

\begin{abstract}
Previous case reports in this series on Education and Training have looked at specialist courses for postgraduate students seeking an in-depth knowledge of informatics and a career in the field. By contrast, this review describes a project designed to pilot a series of learning opportunities for undergraduate medical students. Although some UK medical colleges have opted to introduce informatics into the curriculum as a discipline in its own right, the Informatics Department at St Bartholomew's Hospital Medical College chose a different approach. When a new curriculum was introduced at St Bartholomew's and at The London Hospital Medical College, the Head of the Informatics Department saw this as an ideal opportunity to explore ways of integrating informatics into the curriculum. The initiatives described in this paper were made possible as a result of an award from the UK government Department of Employment. Money from an Enterprise in Higher Education grant funded a range of programmes, one of which was designed to introduce students to selected aspects of informatics and to demonstrate what is feasible in the undergraduate curriculum. The work carried out over a period of three and a half years was intended to provide the basis for the next phase of curriculum development. However, in the wake of the restructuring which has taken place in London medical colleges, the Informatics Department at what was St Bartholomew's has relocated to University College London Medical School, and is now called The Centre for Health Informatics and Multiprofessional Education (CHIME). University College is designing a new medical curriculum and CHIME is drawing on the experience gained through the Enterprise Project to find the best way to integrate informatics into this curriculum.
\end{abstract}

Keywords: Medical Informatics, Medical Education, Undergraduate Medical Curriculum

graduates are not adequately prepared for the challenges they face once they have qualified. A particular concern is that teacher-centred methods of education do not equip professionals to be life-long learners [3]. A second worry relates to where we train doctors. Historically, medical schools have been affiliated to hospitals which have provided the source material (i.e., patients) for clinical teaching. Today, as length of hospital stay gets ever shorter and as more and more patients are treated in day-care clinics or in the community, there is a shortage of pa- tients for teaching purposes. Consequently, most schools are looking to find ways to move students out of hospitals and into community settings [4]. A third critique of medical education relates to the teaching of clinical skills; there is a worry that medical education has lost sight of their importance. To remedy this, medical schools are introducing more structured methods of teaching and assessing clinical skills and many are building clinical skills laboratories [5]. It is against this general background that medical informatics educators must decide how 
and where informatics fits into the curriculum.

\section{The General Medical Council} Review of Undergraduate Medical

\section{Education}

In 1993, the UK General Medical Council (GMC) Education Committee published a set of recommendations aimed at improving basic medical education [6]. Although the GMC document did not use the phrase 'medical informatics', several of its recommendations have implications for informatics teaching in the context of undergraduate education. The most significant thread running through the review is that educators must reduce the amount of factual overload which results in uncritical memorising of facts and neglect of critical appraisal. These criticisms have stimulated an interest in a range of new approaches, such as problem-based learning and evidencebased medicine. Medical informatics has a twofold role to play in enabling medical schools to meet these challenges. On the one hand, curriculum managers look to informatics groups to provide useful electronic tools and resources for education, such as standard software packages, specially designed courseware, bibliographic databases, email and Internet links. Easy access to high quality information is essential to the new types of curricula. The second role for informatics is to stimulate the faculty to think about the nature of medical information and to make students aware of their role in the information cycle [7].

\section{The Medical Informatics Department at St Bartholomew's Hospital Medical College}

The Medical Informatics Department was established in 1988 , under the leadership of Professor Ingram, the first UK Professor of Medical
Informatics. The Department initially comprised six full-time staff. It had an established track record in the design and development of computer-based learning resources. These included the MacSeries, in use throughout the world to model the human cardiovascular and respiratory systems and human drug kinetics, as well as a range of interactive videodiscs used in cancer education and in anatomy teaching. It played a leading role in establishing the computer networks and services shared between the college and hospital and an information systems committee chaired by Professor Ingram had oversight of all administrative and academic computing services.

One of the unique features of the Department was that it was located in adivision of the medical college which included general practice and primary care, clinical skills and medical education. Consequently, the informatics staff worked closely with clinicians, health service researchers and medical educationalists, as well as basic medical scientists, computer scientists and medical physicists. This meant that the Department was well placed to make a major contribution to the new curriculum which was launched in 1990. Equally important, the Dean of the medical college was very supportive of plans to include informatics in the new programme, as part of a new initiative in teaching clinical skills to medical and nursing students.

The department took the lead in developing the first UK clinical skills teaching laboratory, jointly with the local college of nursing and pioneered common approaches between the professions in teaching and assessing clinical skills [8]. A main focus of this work was the development of IT and informatics skills in the context of general clinical skills [9]. Electronic health care records were seen to be central to many aspects of new developments in clinical education [10]. Between 1992-95, the department was the coordinating partner in the Good European Health Record Project which developed the GEHR architecture and object model as a formalism to capture the generic content and context of the clinical record and make it available in ethical and legal clinical practice [11]. The work shaped evolving ideas of how informatics could best be integrated within clinical curricula of the medical school [12-15].

\section{A Window of Opportunity for Developing Medical Informatics Within the New Curriculum}

In the late 1980s, the UK government funded the Enterprise in Higher Education initiative (EHE) to support institutions seeking to promote changes in teaching and learning styles. EHE was also intended to encourage education establishments to form partnerships with industry, commerce and the voluntary and public sector. The programme was managed not by the Department of Education but by the Department of Employment and the goal was to enable graduates to gain enterprising skills which have tended to be neglected by traditional university education.

Educational institutions throughout the country were invited to submit proposals which specified their aims and objectives for achieving change over a5-year period. St Bartholomew's Medical College and The London Hospital Medical College, successfully bid for EHE money; $£ 0.8$ million was allocated to the project [16]. The Enterprise Project was set up shortly after the first intake of students were enrolled on the new curriculum.

\section{The new medical curriculum at Barts and The London}

Students beginning their medical and dental studies at Bart's and The London in the autumn of 1990 , en- 
rolled on a five-year course, divided into three phases and leading to an $\mathrm{MB}$ BS degree. This new curriculum had the following features:

- a reduction in the amount of factual content,

- a shift from didactic teaching to self-directed learning,

- clearly defined core objectives,

- the introduction of projects and options (called special study modules),

- agreateremphasis on the behavioural sciences and medical ethics, and

- new assessment methods.

The Enterprise project provided resources to launch the new curriculum and also made it possible to introduce several new themes to the course. A number of new posts were funded, including a Senior Lectureship in Medical Informatics.

\section{Informatics Initiatives}

Informatics initiatives were developed for all three phases of the medical curriculum and were evaluated in a variety of ways (e.g. through questionnaires, student focus groups and feedback forms completed by tutors). Throughout the project we worked to develop links with curriculum working groups, service units, and clinical tutors. Our mission, as we saw it, was to win allies by demonstrating that informatics has a role to play in the undergraduate curriculum. Where appropriate, we helped to set up new structures to support and manage the informatics activities. What we wanted to achieve was a greater awareness amongst the faculty that informatics needs to be a core theme in the course (in much the same way as communication skills and clinical skills are) and that all tutors have a role to play in getting students to "buy-in" to the information culture. The high level support of the Dean, Professor Lesley Reed, and her initiatives in develop- ing informatics education and clinical skills, side-by-side, greatly facilitated the making of this case.

\section{The Student Body}

The annual intake at Bart's and The London is about 220 students. Approximately half the intake are women. In the UK, medicine is not a graduate entry profession. Most entrants are 1819 years of age and begin their studies as soon as they have completed their final school examination. The most common choice of A-level subjects for medical students are chemistry (required), physics, mathematics and biology. Very few students have had any formal exposure to computing and surveys indicate that the level of computer literacy amongst medical students is no different from that of entrants to other faculties. (About 30\% claim to have used a computer, but this figure conceals great differences. One or two of these students may be competent programmers, but the majority will have used a wordprocessing package and played computer games.) In the UK, it is extremely rare for students to have keyboard skills $[17,18]$.

\section{Phase I (Basic Medical Sciences)}

During the first 5 terms, the emphasis was on basic computer literacy. Workshops were scheduled to introduce students to the facilities available in the faculty and to teach them how to wordprocess their assignments. These workshops were scheduled so as to support students when they were writing up their first major piece of coursework. This initiative was evaluated annually by the Student Enterprise Officer, the Informatics Coordinator and a working group in the Faculty of Basic Medical Sciences. We found that students were very keen to be provided a structured introduction to the computing resources. Attendance was very high (above $90 \%$ of the student body). We also carried out a survey of our incoming student body to assess their learning needs. Our findings about our own student group confirmed the findings of various studies reported in the literature $[17,18]$.

A number of other Phase I activities introduced students to the concepts, methods and tools of informatics. All students were scheduled to attend a session at the start of the course to introduce them to Medline. Students were required to use computers for data capture and analysis in their biometry course, and in laboratory practicals. Several modules made use of computer-assisted learning programmes and tutors were encouraged to start developing question banks for use with a computerised assessment package. Although the Faculty of Basic Medical Sciences did not have a learning resource centre with computers for self-directed study, we found that groups of students started to look to the computer as a way of enhancing their presentational skills. They started to use their word processing skills to make overheads, to produce handouts, leaflets, and posters. Again, the need for these skills was very much driven by the dictates of the curriculum. The Community Module, which introduced students to our diverse local communities and their health care needs, required students to communicate the results of their work in very imaginative ways [19].

\section{Phase II (Introduction to Clinical Skills)}

We identified a number of opportunities in this part of the course for introducing informatics, for demonstrating systems, and building on the foundations laid in Phase I. There were two key areas where informatics was included: in the Projects and in the Clinical Skills Course (which included a communication skills workbook assignment).

The workbook assignment required students to learn how to elicit information from patients which could be used 
for a variety of purposes: problem identification, diagnosis, treatment planning and patient education. The course was taught alongside sociology, psychology and medical ethics. Students were assigned a patient to interview and for assessment they submitted a structured case study report of their experience of interacting with the patient, together with a tape of the interview [20]. In the course of working on their communication skills, students gained experience in clinical data capture and in data recording. The clinical skills focus of this part of the course made this a natural time to introduce students to the hospital's patient information system. We were able to provide hands-on experience without breaching confidentiality because we had a 'training system' which did not contain real patient data. In the course of giving students the chance to search the system and to input data, generic issues to do with data capture, data quality, and data protection were raised.

The Medical Informatics Department at St Bartholomew's has been actively engaged in developing a wide range of computer-based learning resources for the past fifteen years. The programmes produced range from simulations in the Mac series, to interactive videos, image databases and, CD-ROM and Internet-based tutorials (The Tropical Medicine Resource for the Wellcome Trust) [21]. Tutors associated with the clinical skills part of the course were given instruction in how to use these packages. Computers were made available in the newlybuilt clinical skills lab and in an adjacent location so that students could access these resources for revision and self-directed study.

The other component of the curriculum which was linked to informatics teaching was the Phase II Project. The new curriculum required all students to carry out a small scale project and to submit a report. Enter- prise funds were used to appoint a Projects Co-ordinator whose role it was to find persons and organisations willing to offer projects each year [22]. The Senior Lecturer in Informatics, worked with the Projects Co-ordinator and staff in the Computer Services Department to design a modular workshop programme covering a variety of informatics topics such as advanced Medline searching; the design of data collection instruments; data analysis using computer packages such as SPSS; spreadsheets and databases. These sessions were advertised and students were asked to attend relevant sessions. Over the course of several years, a variety of documents, handbooks and online notes were prepared to support these sessions. In the evaluation of student projects, when asked to cite what skills they had learned in the course of their projects, more than $30 \%$ mentioned IT and information handling.

The Project component of the course provided a second 'hook' for informatics initiatives in that each year we offered at least one informatics project to students. During the period covered by this report, the following projects were run:

- General Practice computer systems,

- Electronic Learning Resources,

- Patient Records and Medical Education [23],

- Records of Achievement, and

- Legal and Ethical Issues relating to Health Records [24].

All of these projects had direct links with the major research foci of the Informatics Department, vizelectronic patient records, GP systems, and electronic learning resources to support medical education.

\section{Phase III (The Clinical Component)}

In keeping with the recommendations of the GMC, our medical schools introduced what are called Special Study Modules for final-year clinical students. The purpose of these modules is to allow students to:

- study a subject of their choice in depth, and

- develop skills of independent study and self-directed learning.

Final-year clinical students select three special study modules, each lasting for 4 weeks. All tutors are free to propose a special study module. Whether a module runs is dependent on student choice. (The same module is generally offered twice each academic year.) The Informatics Department designed and supervised a module in medical informatics. At the start of the module students are asked to draw up a learning contract and a programme of activities is negotiated. The key activities during the four week block have included attending a series of lectures and seminars, attending a major international conference on Medical Informatics, carrying out a structured programme of reading, working on IT skills, and carrying out a series of visits and interviews to informatics research sites. We were very fortunate that ten different agencies and research teams were prepared to support the module by demonstrating their systems, outlining their research and giving their views on the "grand challenges in medical informatics". At the end of the month, students are required to produce a report reviewing what they have learned, together with their analysis of one topic which they have researched indepth. Feedback both from the first student to take the module and from the various external groups who had participated in the exercise suggest that this is a successful method of engaging final year clinical students in the field of informatics.

\section{Intercalated Degree Students: the BMedSci Course}

As well as working with students in the five year programme, our brief 
also extended to students taking what is called an intercalated degree. UK medical students are allowed to take a year's leave from their normal programme to study for a BSc degree. The majority of students exercising this choice opt for a degree in one of the basic medical sciences (eg anatomy, physiology, endocrinology, immunology) but students are free to choose other subjects such as epidemiology or psychology. At the same time that the new undergraduate medical curriculum was launched, $\mathrm{St}$ Bartholomew's Hospital Medical College created a new intercalated course, leading to a BMedSci degree. This course was different from most existing courses because instead of admitting students at the end of their preclinical course, it recruited students who had completed the first two years of their clinical studies.

The core module of this course occupied the whole of the first term of study and was led by the Informatics Department. Students attended a series of IT workshops and 3, three-hour sessions designed to demonstrate the relevance of informatics to clinicians. The course was topic-based and students were required to answer a question on the examination. The topics chosen for the 'case studies' (health care records, clinical decision making, mathematical modelling and simulation, and telemedicine and telecare) reflected the interest and expertise of the Medical Informatics Department. A particularly effective practical assignment linked bioanalysis of samples from an insulin clearance experiment, spreadsheet analysis of kinetic parameters and simulation of results using the Mupharm human drug kinetic program developed in the Department [25]. The informatics component of the BMedSci course has provided the template for a very successful core module and elective at St George's Hospital Medical School (part of their MSc in Health Sciences).

\section{Staff development Activities}

Staff development was a focus for the entire Enterprise Team. On the informatics side, regular workshops were organised in response to requests from the deans, heads of department and tutors. During the period covered by this report, most tutors were preoccupied with writing learning objectives, preparing new courses and thinking about teaching methods. What most tutors wanted us to provide was help in learning about computer-based learning resources $[26,27]$. We ran two different types of workshops: one type was organised with commercial courseware producers and allowed tutors to see some of the latest multimedia products; other sessions were designed to address broader issues of how to implement these resources into the curriculum. In addition, staff in the medical informatics group provided consultancy to tutors thinking of producing their own materials. One disappointment was that very few tutors spontaneously raised queries about where, how or whether informatics was relevant to what they were teaching. These broader issues were just starting to come to the fore as some tutors became interested in teaching evidence-based approaches to healthcare.

\section{Discussion}

The starting point for this project was our belief that information handling skills are an integral part of clinical practice. Our goal was to explore how to integrate informatics into the undergraduate curriculum so as to lay the foundations for future professional development. Looking back at what we achieved, we remain convinced that the best way to introduce undergraduate students to informatics is not by developing specialist courses, but by showing how the tools and con- cepts of informatics can support the curriculum. What we are advocating is a pragmatic approach which seeks to demonstrate how informatics can i) support students in their learning role; ii) prepare students for their future clinical role; and iii) support faculty in their teaching role.

New developments in medical education, and changes in our national health service, are creating a climate which is receptive to suggestions from the informatics community [26]. There is growing evidence that problembased learning, evidence-based medicine and community-based medical education will require both investment in technological infrastructure and a coherent educational philosophy for introducing students to electronic tools and information sources. The audit of clinical practice, the demonstration of clinical competence and the use of guidelines and decision support in pursuit of the highest quality of clinical care and clinical outcome have all been identified as national priorities [28]. To facilitate these objectives, the National Health Service's Information Management and Technology strategy places patient-centred information systems high on the agenda. This in turn provides a focus for the research and development work of informatics.

What follows from this analysis is the need for centres of informatics to work closely with medical education departments, medical libraries, teaching hospitals and clinical tutors, so as to develop a coherent approach both to information provision and to teaching. Informatics specialists have a major role to play in medical education. They can help to develop the information strategy for the medical school; they can encourage the faculty to teach students good practice in relation to clinical data; they can provide learning opportunities for students in the form of attachments and projects; they can assist in developing learning re- 
sources; and they can advise on the infrastructure needed to support new ways of learning and of practising medicine using information technology.

Acknowledgement: This work was supported by an Enterprise in Higher Education Award from the Department of Employment, and by the Special Trustees of St Bartholomew's Hospital. The success of the project was very dependent on the contribution made by the following colleagues: Dr Jane Dacre, Dr Brian Jolly, Mr William Howard, Mr Anthony Peacock, Dr Peter McCrorie, and Professor Lesley Rees.

\section{References}

1. Parsell GJ, Bligh J. The changing context of undergraduate medical education. Postgrad Med J 1995;71:397-403.

2. Schatz IJ. Changes in Undergraduate Medical Education: A critique. Arch Intern Med 1993;153:1045-52.

3. Rosenberg W, Donald A. Evidence based medicine: an approach to clinical problemsolving. Brit Med J 1995;310:1122-26.

4. Schmidt HG, Alausa OK, eds. New directions for medical education: Frontiers of primary care. New York: Springer-Verlag, 1989.

5. Dacre JE. Teaching clinical skills. Med Educ Review Autumn 1992:7.

6. General Medical Council. Tomorrow's Doctors: Recommendations on Undergraduate MedicalEducation.London:General Medical Council, 1993.

7. Murphy J. Education for Medical Informatics. Health Libraries Review 1994;11:167-76.

8. Dacre JE,Nicol M. ClinicalSkills: Alearming matrix for students. Abington Oxon: Radcliffe Medical Press, 1996.

9. Cull P, Dacre J, Ingram D. A challenge for change. The clinical skills and self directed learning centre at St Bartholomew's Hospital. Computers in Teaching Initiative, Centre for Medicine. Update 1992;3:16.

10. Weed LL. The premises and tools of medical care and medical education: perspectives over 40 years. In: Blum BI, Duncan K, eds. A History of Medical Informatics. New York: Addison-Wesley, 1990:223-49.

11. Ingram D. The Good European Health Record Project. Proceedings of the AIMCEN European Workshop on the Medical Record. Brussels: EC, 1993.

12. Murphy J, Griffith S, Duddle J, Machado
M. Educational Requirements of GEHR Architecture \& Systems, GEHR Project A2014. DeliverableNo 9, StBartholomew's Hospital Medical College, 1993.

13. Murphy J, Griffith, S, Ingram D. How can electronic healthcare records benefit clinical students? In: Richards B, et al, eds. Current Perspectives in Healthcare Computing. Surrey: BJHC Ltd, 1995:162-72.

14. Murphy J. Teaching and Learning Medicine in the Year 2000: The Impact of Electronic Learning Resources (In press. To be published in Proceedings for the CTI Centre for Medicine Conference: Production and Delivery of Computer Based Learning, Bristol, September 1995.)

15. Griffith S, Murphy J, Southgate LJ. Unlocking the potential of clinical records as a resource for medical education. In: Rothman AI, Cohen R, eds. Proceedings of the Sixth Ottawa Conference on Medical Education. Toronto: University of Toronto, 1995:554-6.

16. Enterprise in Higher Education. City and East London Confederation for Medicine and Dentistry. Annual Reports: 1991-1996.

17. Osman LM, Muir AL. Computer skills and attitudes to computer-aided learning among medical students. Med Educ 1994;28:3815.

18. Jones RB et al. Computer literacy among medical, dental, nursing and veterinary undergraduates. Med Educ 1991;25:191-5.

19. Wykurz GP. Community Partnership in the Assessment of Community-Based Learning. In: Rothman AI, Cohen R, eds. Proceedings of the Sixth Ottawa Conference on Medical Education. Toronto: University of Toronto, 1995:572-6.

20. Jolly BC, et al. Reliability and validity of a patient based workbook for assessment of clinical and communication skills. In: Rothman AI, Cohen R, eds. Proceedings of the Sixth Ottawa Conference on Medical Education. Toronto: University of Toronto, 1995:248-52.

21. Howard W, Williams B. Computer Based Learning via The Internet: The problems of reaching the masses. Poster presented at the CTI Centre for Medicine Conference, September 1995.

(hhtp://www.chime.ucl.ac.uk/ECDU/Posters/CTICM95/)

22. Harris GA. Project Work for Medical Students with Employers in Fields Related to Medicine. In: Rothman AI, Cohen R, eds. Proceedings of the Sixth Ottawa Conference on Medical Education. Toronto: University of Toronto, 1995:577-81.

23. Murphy J, Curtis R, Green S. Training in Medical Informatics: findings from UK survey. In: Richards B, ed. Current Perspectives in Healthcare Computing. Sur- vey: BJHC Ltd, 1994:812.

24. Ingram D, Southgate L, Heard S, Doyle L, Kalra D, et al. GEHR Requirements for Ethical and Legal Acceptability. The Good European Health Record Project, Deliverable No. 8. AIM Office, Brussels, 1993.

25. Saunders L, Ingram D, Jackson SJ. Human Drug Kinetics. Oxford: University Press, 1989.

26. Murphy J. Staff Development in Relation to Computer-Based Learning. In: Towle A, ed. Effecting change through staff development: Sharing Ideas 2. London: Kings Fund Centre, 1993:30-2.

27. Peacock A, Howard W, Ingram D. Digital video: what, when and why? A practical overview for multimedia authors, based on case studies. (In press. To be published in Proceedings for the CTI Centre for Medicine Conference: Production and Delivery of Computer Based Learning, Bristol, September 1995.)

[http://www.chime.ucl.ac.uk/ECDU/Papers/CTICM95/]

28. NHS Executive. Promoting Clinical Effectiveness: A framework for action in and through the NHS. 1996.

Address of the authors:

David Ingram, Jeanette Murphy,

Centre for Health Informatics and

Multiprofessional Education (CHIME),

University College London Medical School, Whittington Campus,

4th Floor Archway Wing, Highgate Hill,

London N19 5NF, United Kingdom.

(both authors were previously in the Medical Informatics Department at St Bartholomew's Hospital Medical College) 